\section{International Scientific Journal Theoretical \& Applied Science}

p-ISSN: 2308-4944 (print)

e-ISSN: 2409-0085 (online)

Year: 2015

Issue: 02

Volume: 2

Published: 28.02.2015

http://www.T-Science.org
Gulmira Kuttybayeva

Masters of Economic,

Candidate of Economic Science,

Visiting Scholar of University of Wolverhampton,

United Kingdom

g.kuttybayeva@yahoo.com

SECTION 19. Management. Marketing. Public administration.

\title{
PREPARATION OF SERVICE QUALITY IN KAZAKHSTAN: CASE STUDY OF EXPO-2017
}

\begin{abstract}
Current study is based on the case study of Kazakhstan, Astana for EXPO 2017. The hotel industry in Astana, despite the presence of luxury hotels, is slightly inferior to the hospitality industry in many European cities in the metropolitan level. The upcoming major international event of EXPO 2017 will require the presence of a large and variety of accommodations. Astana now attracts a large number of business travelers who come here in order to solve business issues. According to Ministry of National Economy of the Republic of Kazakhstan Committee on Statistics the number of visitors in 2013 was 6, 8 million, but only $1 \%$ of visitors had a tourism purpose. After successful participation in EXPO-2008 in Saragossa where Kazakhstan took third place among 104 participating countries, the Bureau International des Expositions voted to select Astana, Kazakhstan as the host of Expo 2017. Based on the above, it can be expected that the EXPO 2017 will be one of the key events in the recent history of Kazakhstan, and the holding of this event will make a huge contribution to the image of the country, the economy and culture. Kazakhstan's economic growth in recent years is closely aligned with tourism development and following a successful bid to host Expo 2017, its hospitality and tourism industry faces a new set of opportunities and challenges. Considering these impacts current case study will discuses the changes happened among accommodation providers in Astana in order to enhancing the quality of services for potential tourist in Expo2017.

Key words: hotel industry, EXPO, Kazakhstan, mega-events, service quality.

Language: English

Citation: Kuttybayeva G (2015) PREPARATION OF SERVICE QUALITY IN KAZAKHSTAN: CASE STUDY OF EXPO-2017. ISJ Theoretical \& Applied Science 02 (22): 48-54. doi:
\end{abstract} http://dx.doi.org/10.15863/TAS.2015.02.22.10

\section{Introduction}

One of the largest international expos of the decade is coming to Astana to the capital of Kazakhstan. On November 22, 2012, the 156 member nations of the International Exhibitions Bureau (BIE) met in Paris and decided by an overwhelming majority vote of 103 countries that EXPO 2017 will be held in Astana. EXPO 2017 is a recognized expo, also referred to as an international specialized expo, and is part of the World's Fair system. Recognized expos are smaller versions of the Universal expos commonly referred to as World's Fairs. Recognized expos center on a particular theme and are held between World's Fairs, which occur every five years. Kazakhstan has chosen the theme "Future Energy" to promote and discover sustainable, global energy solutions. Hosting recognized expos, like hosting universal World's Fairs, World Cups or the Olympics is a major coup for any nation. The events bring hundreds of millions of dollars in revenue and immeasurable international exposure to the culture and economy of the host nation [1]

EXPO-2017 in Astana last 3 months - from June 10 to September 10, 2017. It is expected that it will take part in around 100 countries and 10 international organizations. Already allocated a special area for the exhibition, a total area of 113 hectares, while the area of the pavilion will be 25 hectares.

All of the above is talking about a huge responsibility for the conduct of the event. Especially because this is the first such event held in Kazakhstan. One of the important moments is a sufficient number of hotels and high quality services for guests arriving. The present study investigates the preparation of hospitality industry in Kazakhstan. Obviously, the hotel industry in Kazakhstan is not 
well developed and its development requires large investments. Analysis of the current situation of training services the hotel industry is considered in this study.

\section{History of EXPO}

In our study, we cannot ignore the history of the creation of exhibitions EXPO. The history of Expo shows how unique and prestigious event and what it means for the host country.

History of World's Fairs starts with "the Great Exhibition of the Works of Industry of all Nations" held in London in 1851 and continues up to this day. In 1928 the International Exhibitions Bureau (BIE) was founded in Paris to oversee the exhibition activity. The International Exhibitions Bureau monitors compliance with the principles and objectives of the Universal Expositions; in the framework of international cooperation it holds events in education and innovation fields and conducts meetings to exchange viewpoints and develop a global dialogue on mankind problems.

According to International Exhibitions Bureau, Venues for the World's Fairs and their themes are determined by taking into account political, economic, geographical and cultural contexts. In the XIX century the Industrial Revolution, movements of Romanticism and Positivism create favorable conditions for the phenomenon of expositions. Since their inception the Expositions have been a manifestation of solidarity among nations; thus, they simultaneously become both "showcase" and forums discussing issues related to the progress of mankind. Occasionally the solemn dates are celebrated along with Universal Expositions; EXPO becomes a link between the past, present and future. Thus, in 1889 in Paris the Centennial of the French Revolution is celebrated, 1876 EXPO in Philadelphia marks the 100th anniversary of the signing of the Declaration of Independence of the USA; 1893 EXPO in Chicago and 1992 EXPO in Seville commemorate the 500th anniversary of the discovery of Americas, and 1915 EXPO in San Francisco celebrates the completion of the Panama Canal [1]

Kazakhstan introduced its pavilion at the Expo 2012 . The pavilion was built in Kazakhstan taking into account traditions and innovations in culture and science, business and tourism. The pavilion was dedicated to the theme of water, and narrated the history and traditions of Kazakhstan, its modern life and its prospects for the future. Visitors saw and participated in interactive show, which was broadcast around the pavilion. This participation was a rewarding experience for Kazakhstan.

The host countries have extensive experience, which is necessary for Kazakhstan. The history of Expo shows about the benefits which gives that event, such as the development of tourism and raising the image of the country.

\section{Astana - the host of EXPO 2017}

As we have said, Expo 2017 will be held in Astana - one of the youngest capitals of the world, which has received the status of capital in 1997. In 1999 on the initiative of UNESCO, it was awarded the title of the City of Peace. Astana population is 829,000 people, and its area - 722 square kilometers. Due to the special economic zone the city became the center of the construction of modern architectural complexes involving such famous architects as Kisho Kurokawa, and Norman Foster. Like the majority of world capitals, Astana has its symbol, Baiterek monument, which represents the tree of life [2].

According to experts, the government of Kazakhstan has allocated 250 million euros $(\$ 325.25$ million) to construct the EXPO site and build a new generation of mass transit and roads to serve it. The government also expects to attract 1 billion euros ( $\$ 1.3$ billion) in foreign investments for the new buildings, roads and transit systems, including a new city railway system. This includes the costs of constructing the exhibition pavilions and new hotels for visitors and it is in line with the average amount spent on holding other EXPOs around the world [4, p.97].

\section{Astana}

The currently situation in hotel industry in

According to Agency of Statistic of Republic of Kazakhstan, the currently situation in hotel industry in Kazakhstan is significantly improved over the past 2 years .

The line graph shows the movement of hotels during the period of 4 years. In the 2011-2012 years there were no any changes, but afterwards the number of hotels increased significantly with positive trend in future. As it is seen in the line graph, the number of small enterprises of hotel business in 2013 cost was 1678 [3]. 


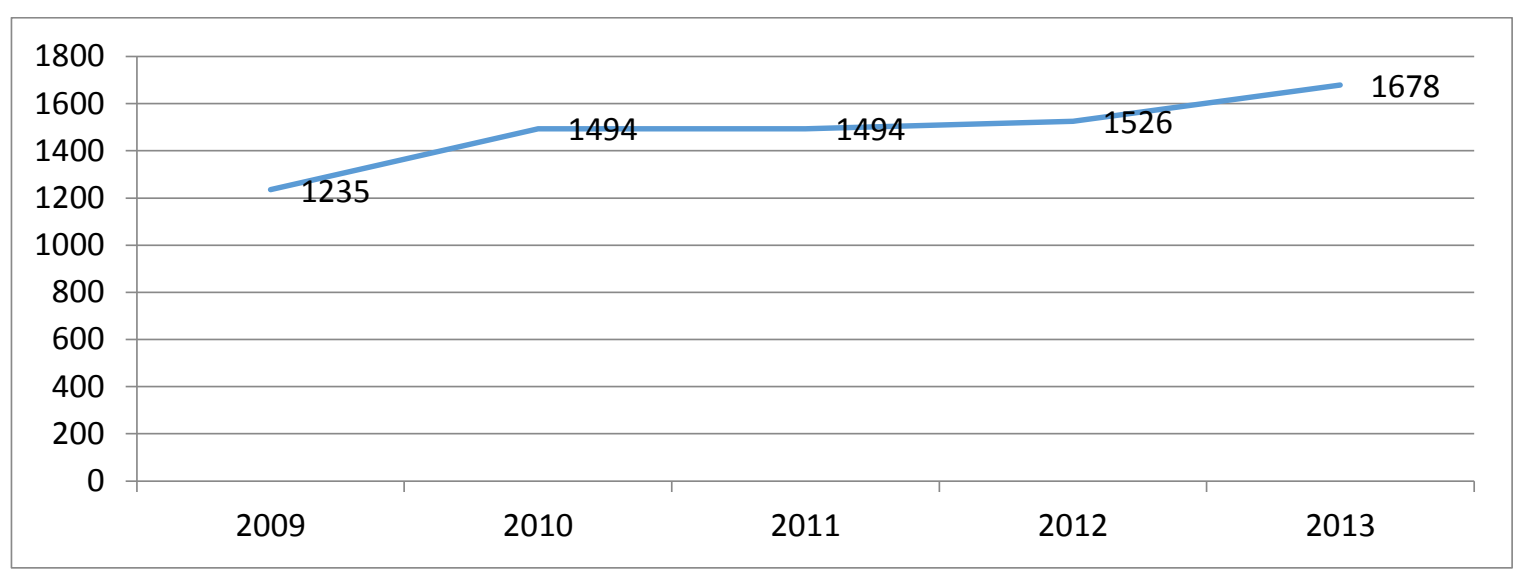

Picture 1 - Main trends in accommodation and placement in Kazakhstan.

Hotel industry directly depends on the dynamics of growth of visitors coming to the RK, as $68,8 \%$ ofustomers who used hotels services in 2013 were RK residents [4, p.48].

The leaders in the numbers of customers, who used hotel services is Astana city. According to Department of Statistic, as of January 1, 2014 in Astana operated 141 hotels (including individual entrepreneurs), providing their services to visitors and residents of the city. Over 2013 hotels of the city served 608.3 thousand visitors. Compared with 2012 the number of served visitors increased by $9.3 \%$ or 51.7 thousand. Visiting tourists accommodated in hotels with 141 one-time capacity in their 9124 beds and the number of rooms - 5484, among which are the hotels belonging to the category of 3-5 star hotels and, accordingly, meet internationally accepted standards («Ramada plaza» - 5 star, «Radisson Sas» 5 star, «Rixos President hotel Astana» - 5 star, «Pekin Palace Solacs hotel Astana» - 5 star, "Empire G» - 4star, "Grand Park Yesil" - 4 star, "Mukammal" - 4 star, "Altyn Dala" - 4 star, "Silk Way" - 4 star, «Manhattan Astana Hotel» - 4 star, "Duman" - 4 star "Sunkar" - 3 star, «Tengri» - 3 star, "Everest" - 3 star).

\section{The numbers of hotels in Astana.}

Table 1

\begin{tabular}{|c|c|c|c|c|c|}
\hline Type & 2009 & 2010 & 2011 & 2012 & 2013 \\
\hline Total amount & 107 & 120 & 134 & 140 & 141 \\
\hline 5 star & 4 & 4 & 4 & 4 & 10 \\
\hline 4 star & 3 & 7 & 10 & 18 & 11 \\
\hline 3 star & 15 & 2 & 2 & 2 & 19 \\
\hline 2 star & 2 & 90 & 99 & 106 & 2 \\
\hline no category & 52 & 90 & & 105 \\
\hline
\end{tabular}

Source: $\underline{w w w . a s t a n a . s t a t . k z}$

As can be seen from Pic. 2, the main number of hotels in Astana hotels make no category-75\%, while the 5 star hotels only $3 \%$ of the total. 


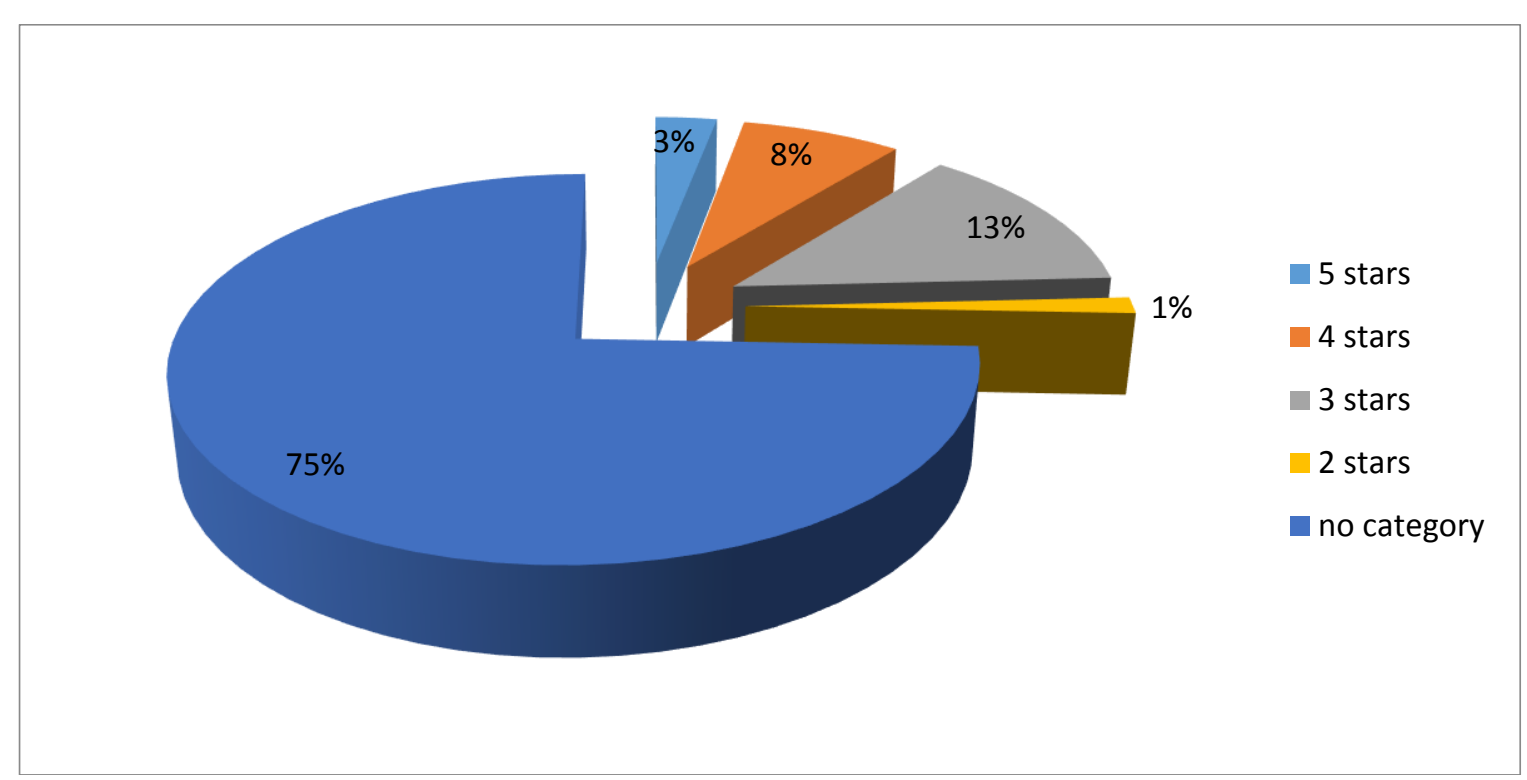

Picture 2 - Hotels by category in Astana, 2013.

Another problem for hotels in Astana is a low hotel occupancy. For instance, the hotel occupancy in 2013 was only $33.9 \%$, compared with 2012 decreased by $0.6 \%$. (Table 3 ). It should be noted that the decline is not looking at the average cost per bedday, which was 10,731 tenge (\$59) in 2013, which is less than 2,600 tenge ( $\$ 15)$ than in 2012.

Basic indicators of accommodation facilities in Astana.

Table 2

\begin{tabular}{|c|c|c|c|c|c|}
\hline & 2009 & 2010 & 2011 & 2012 & 2013 \\
\hline Number of rooms, units & 3324 & 4264 & 4694 & 4885 & 5492 \\
\hline Time capacity, beds & 5953 & 7218 & 7798 & 8031 & 9134 \\
\hline Courtesy room nights & 570865 & 748090 & 884940 & 1012769 & 783985 \\
\hline Occupancy, \% & 26,3 & 28,4 & 31,1 & 34,5 & 33,9 \\
\hline $\begin{array}{c}\text { The average cost per bed- } \\
\text { day, tenge }\end{array}$ & 13300,2 & 8995,2 & 10725 & 13300,2 & 10731 \\
\hline $\begin{array}{c}\text { Volume of works and } \\
\text { services, thousand tenge }\end{array}$ & 7577849,0 & 10815062,4 & 13624642,5 & 15068487,8 & 13292428 \\
\hline
\end{tabular}

Source: www.astana.stat.kz

Acccording to Department of Astana, the total amount of visitors in 2013 was 608317, of whom 123186 have preferred to stay in 5 star hotels, 90925 in 4 star hotel, 87780 in 3 star hotels, 4788 in 2 star hotels, 30 hotels 1 star the remaining 291638 visitors prefer to stay in hotels without category [5]. As the table shows, the majority of visitors who are residents of the country, still prefers hotels without category because of low prices. On the other hand, we can see an increase in the number of nonresidents as compared with 2009 - 290,151 visitors by $47 \%$ in 2013 . 
Number of visitors serviced accommodation facility in Astana, people.

Table 3

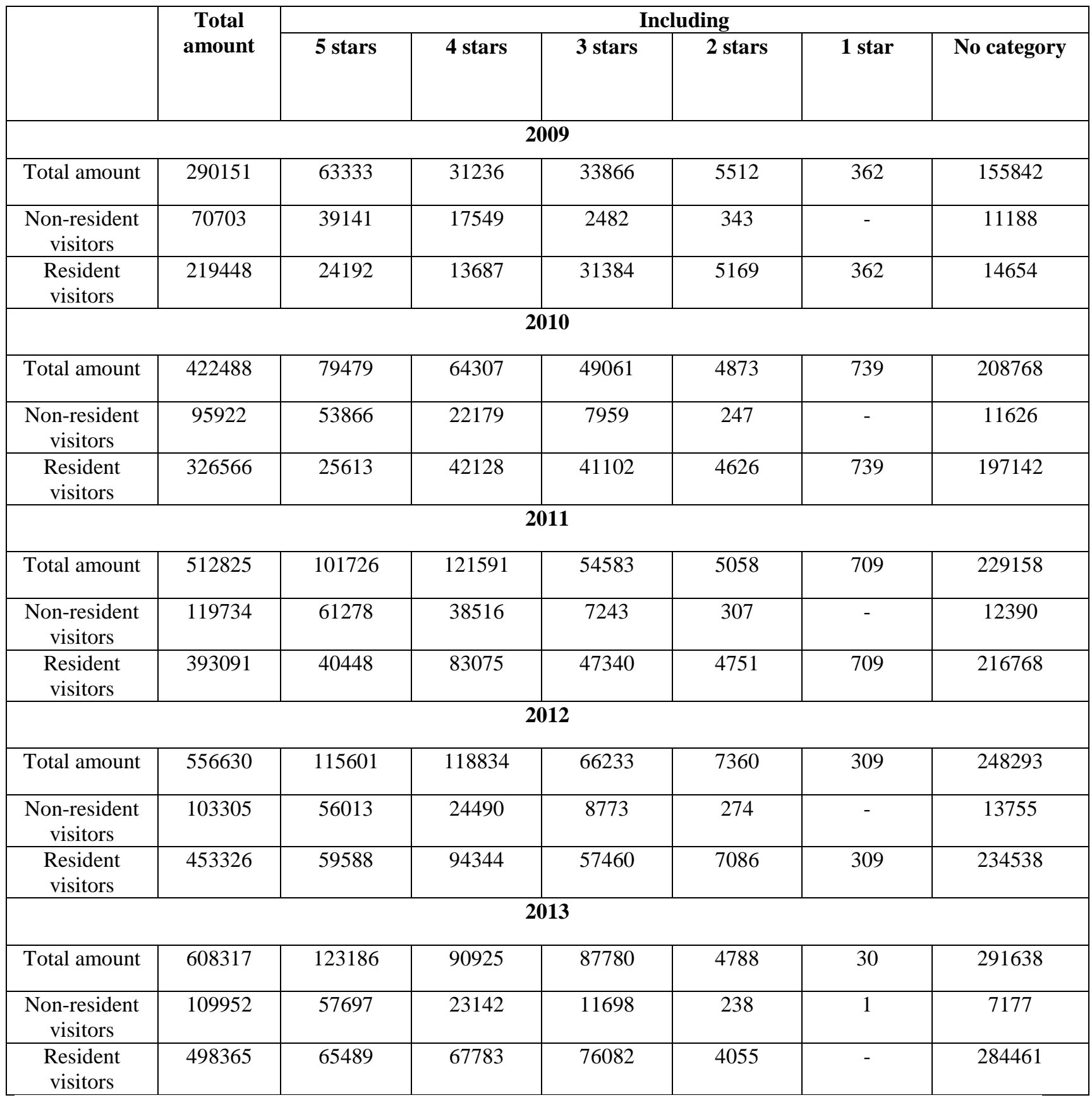

There is no doubt, the number of hotels in Astana is not sufficient for the visitors of EXPO 2017. It is necessary not only to create new best hotels, but also improve the quality of service for visitors.

Research Methods. In the process of writing were used scientific methods such as analysis and synthesis, methods of economic, logical analysis and systematic approach.

\section{Preparation for EXPO}

To date, the hotel market in Astana, despite the presence of luxury hotels, the hospitality industry is slightly inferior to many European cities, the capital level. The hotel market of Kazakhstan's capital started to develop relatively recently. Now the city is represented by hotels of different levels of star. Fivestar hotels in Astana enjoys a privileged geographic location, rich interiors and high-quality original cuisine. Now the city has a market, including hotels that operate under international brands. However, such a major international event like EXPO, Astana

ISPC European Technology in Science, 
will require the presence of a large number of quality hotels [6,p.22]. Being the capital city, Astana is now attracting a large number of business travelers who come here to solve business issues. The capital of Kazakhstan in the near future should be transformed into an interesting direction for travel. The architectural image of the city is constantly changing.

In 2013 Resolution of the Government of the Republic of Kazakhstan was approved by the National Plan of organization and holding of EXPO2017. The National Plan has been identified an extensive list of events administrative, organizational, legal, economic and technical issues related to the preparations for the exhibition. In addition, in January 2013 was created JSC "National Company" Astana EXPO-2017 "with the absolute state participation in the authorized capital, which will serve as the main coordinating role in the implementation of the National Plan. Among the key activities of the National Plan are the following. On the territory of Astana and its suburbs will be built a number of objects, among which will include exhibition hall, eco - and ethnovillage a radius of 30 kilometers from Astana, hotels and holiday homes, service points and shopping centers. In addition, the planned construction of residential areas under the title "Expo City";

As we have said before, to witness such a massive event like EXPO-2017 will want millions of people from around the world. Therefore, in preparation for this grand event, it is important to pay special attention to the reception of foreign guests. According to the Department of Architecture and Urban Planning in Astana, in preparation for the international exhibition EXPO-2017 in Astana announced the construction of 43 new hotels, hotels of international hotel brands Hilton, Marriott, RitzCarlton [6, p.12;7,p.25].

The analysis showed, currently, Astana has 141 registered hotels with a total of 5,492 rooms.. The growth came mostly from the number of lower-range facilities and the opening of the upper-midscale Park Inn by Radisson with 248 rooms. Despite the increase in the total number of rooms, the quality mid-range hotel segment is still under-represented in the capital. Astana has four upscale hotels operating under internationally recognized brands with the total of 744 rooms. The base rate for a standard single room in upscale hotels declined slightly compared to the same period of 2013, staying in the range of $\$ 300$ - \$450, VAT and breakfast included.

The average daily rates of mid-range hotels also decreased slightly. As of the second quarter 2014, the price of accommodation ranges within $\$ 80-\$ 270$, including VAT and breakfast. A new mid-scale branded hotel, the Hilton Garden Inn Astana, has recently commenced operation, increasing the market room stock by 229 units. And the new Marriott opened in Astana on August 1 further expanding the hotel business in the booming capital. Development activity in the Astana hospitality market remains high with ongoing construction including the following projects: IBIS (scheduled to open its doors in the third quarter 2014 as well), The Ritz-Carlton (2017) and Abu Dhabi Plaza (2017) [8,p.32;9,p.40 ]. Subsequently, the current stock is expected to expand by almost a quarter in the next 3 years.

Owners of hotels and catering management in preparation for the EXPO-2017 recommends to pay special attention to the training of personnel English. It is planned to organize training courses. You also need to take care of the inclusion of English in menu texts and placards.

Many experts are concerned about the future use of the huge number of hotels after the exhibition in Astana. After all, there are examples of inefficient use of expensive buildings in other countries. Guide Astana argues that this issue is provided. After the exhibition, some hotels will be transformed into housing for the population and in the construction of hotels, this factor will be taken into account [10,p.44;11,p.53].

\section{Conclusion}

Summing up the results of research in this article should be noted that the preparation for Expo in Astana is rapid. Claimed number of hotels seems to be sufficient to accommodate the visitors. But on the other hand, remains doubtful question about the quality of services in the hotel industry necessary for the international guests.

There is no doubt, an urgent need to pay attention to the training of qualified personnel for the hotel industry, the average cost of living as well as the gap between luxury hotels and hotels with no category is too large as well as in price.

\section{References:}

1. (2015) International Exhibitions Bureau. Available: $\quad$ www.bie-paris.org/site/en/ (Accessed: 15.02.2015). $\begin{array}{lll}\text { 2. } & \text { (2015) EXPO 2017. Available: } \\ & \frac{\text { www.expo2017astana.com }}{15.02 .2015)} & \text { (Accessed: }\end{array}$ 15.02.2015). 
3. (2015) Agency of Statistic of Republic of Kazakhstan. Available: www.state.kz (Accessed: 15.02.2015).

4. (2013) Overview of the tourism industry in Kazakhstan. 2013. Department of Industrial Policy.

5. (2015) Department of Statistic of Astana. Available: www.astana.stat.kzl (Accessed: 15.02.2015).

6. Ustenova OZ, Davletova MD (2015) Hotel Business. Almaty.

7. Smailova AA (2012) Statistical compilation. «Tourism in Kazakhstan in 2011» Stat.compilation. Almaty, Zheti Zhargy.
8. Yulchiyeva GN (2004) Organization of a Hotel Enterprise in the Conditions of Economic Globalization. Almaty.Classica, pp. 458.

9. (2015) Statistical data provided by Kazakhstan Association of Hotels and Restaurants (KAGIR). Available: www.kagir.kz (Accessed: 15.02.2015).

10. Yulchiyeva GN (2010) Hospitality. Theory, practice and prospects for Kazakhstan. Almaty. Publisher:Lem.

11. (2012) Hotel Services Quality Management, 2012. Digest "Development of Economic Thought in Kazakhstan”. Almaty. Economics.

12. (2007) Business Planning in Hospitality Industry, 2007. textbook/ Vinogradova M.V., Moscow: Dashkov and Co., pp. 284. 